\title{
LIPOMA DA CABEÇA DO PÂNCREAS
}

\author{
HEAD PANCRETIC LIPOMA
}

\section{José Huygens Parente Garcia, TCBC- CE ${ }^{1}$ \\ Leonardo Mesquita Sampaio ${ }^{2}$ \\ Denissa Ferreira Gomes Vasconcelos ${ }^{3}$}

\section{INTRODUÇÃO}

As neoplasias primárias do tecido pancreático mesenquimal (fibroso, adiposo e vascular) são raras, como também as originárias do tecido neural e muscular. Elas formam um grupo heterogêneo de lesões benignas, boderlines e malignas.

De 1966 a 1995, foram publicados 64 casos de tumores benignos do tecido conjuntivo frouxo do pâncreas, sendo dois lipomas ${ }^{1}$. Até as últimas publicações, foram relatados cinco casos de lipoma intrapancreático. Pela escassez de informação sobre este tipo de patologia e por esta possuir um diagnóstico diferencial muito preocupante - o adenocarcinoma pancreático - torna-se importante o relato deste caso.

\section{RELATO DO CASO}

Paciente de 51 anos, do sexo feminino, branca, foi admitida com história de episódios esparsos de dor de média intensidade em hipocôndrio direito com irradiação para o dorso e duração de três meses. O exame físico não revelava alterações. A paciente tinha história de diabetes mellitus controlado por dieta, negando o uso crônico de álcool, tabaco ou cirurgias abdominais anteriores. Foi submetida à ecografia do abdome superior com resultado normal. Tomografia computadorizada abdominal revelou massa sólida de $0,5 \mathrm{~cm}$ em topografia de cabeça de pâncreas, rechaçando lateralmente a veia cava inferior e com densidade de tecido adiposo (Figura 1). Os exames laboratoriais, incluindo enzimas hepáticas e pancreáticas, não se mostraram alterados.

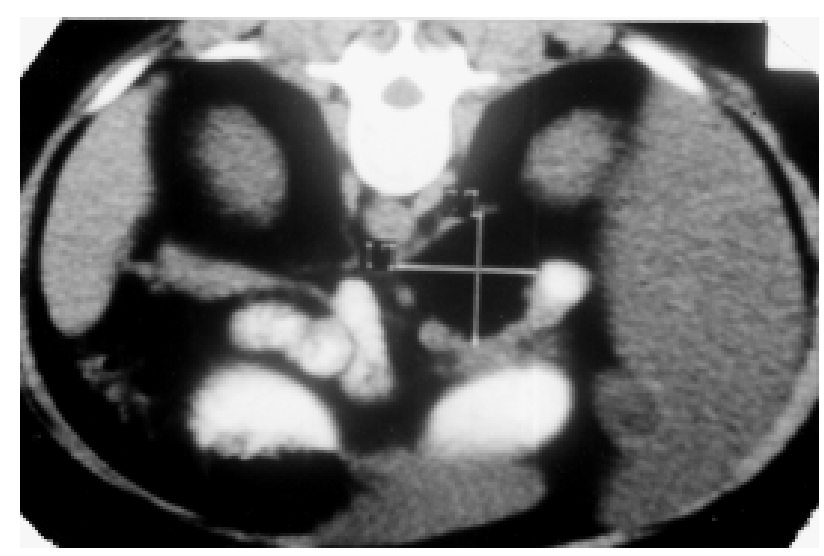

Figura $1-T C$ demonstrando tumor de $5 \mathrm{~cm}$ na cabeça do pâncreas.

Com diagnóstico provável de lipoma de cabeça de pâncreas, foi realizada intervenção cirúrgica através de incisão subcostal direita. Após realização da manobra de Kocher, identificou-se tumor encapsulado em região posterior da cabeça do pâncreas. Após a abertura da cápsula pancreática e dissecção do colédoco retropancreático, o tumor foi enucleado (Figura 2). O exame de congelação foi compatível com lipoma. A paciente recebeu alta no terceiro dia de pós-operatório, sem complicações.

$\mathrm{O}$ exame histopatológico mostrou neoplasia benigna, mesenquimal, formada por adipócitos, delimitados por trechos de tecido pancreático normal.

\section{DISCUSSÃO}

Os tumores benignos originados do pâncreas exócrino são raros.

1. Professor Assistente do Departamento de Cirurgia da Universidade Federal do Ceará

2. Acadêmico de Medicina da Universidade Federal do Ceará

3. Acadêmica de Medicina da Universidade Federal do Ceará

Recebido em 31/07/2000

Aceito para publicação em 20/06/2001

Trabalho realizado no Hospital Universitário Walter Cantídio da Universidade federal do Ceará. 


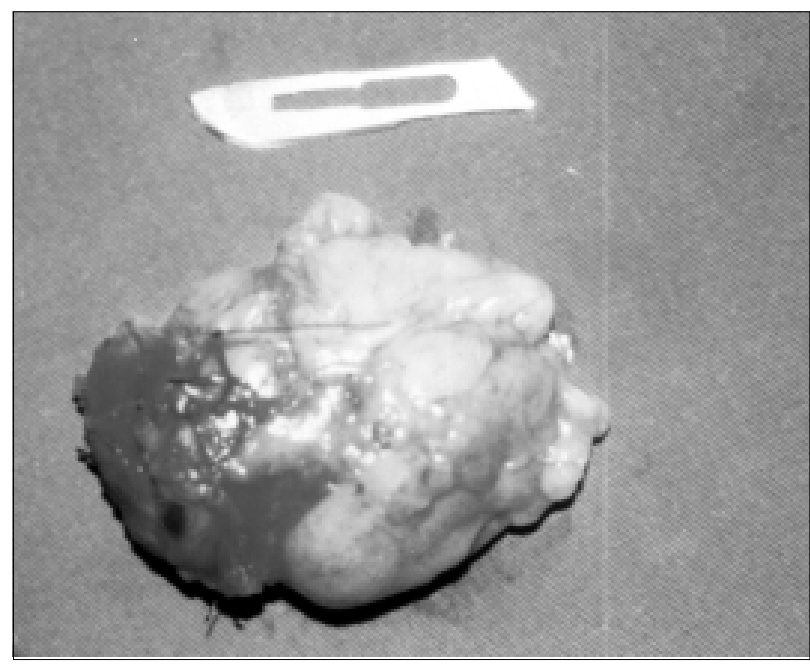

Figura 2 - Peça cirúrgica: lipoma do pâncreas enucleado de $5 \mathrm{~cm}$.

Somente cinco casos de lipoma pancreático foram descritos na literatura, e em geral os pacientes se apresentaram sem comprometimento do estado geral e com discretas alterações nos exames laboratoriais. No primeiro caso relatado, Bigard et al. ${ }^{2}$ descreveram um lipoma de cabeça de pâncreas em uma mulher de 63 anos, detectado por ultra-sonografia (imagem hipoecogênica de $30 \mathrm{~mm}$ ), em que foi feita aspiração por agulha fina percutânea com di- agnóstico de adenocarcinoma. Após duodenopancreatectomia, foi constatado pelo exame histopatológico tratar-se de lipoma e não de adenocarcinoma. Merli et al. ${ }^{3}$ (quarto caso a ser publicado), descreveram outro caso de lipoma de cabeça de pâncreas em mulher de 70 anos, diagnosticado precisamente por TC e seguida por cirurgia conservadora com excisão simples do tumor. Em quatro casos revistos por Katz et al. ${ }^{4}$, os autores mostraram a sensibilidade e a especificidade da TC no diagnóstico de lipoma pancreático em pacientes que apresentavam sintomas vagos de afecção abdominal; foram massas de 2,5 a 5,3cm encapsuladas na cabeça do pâncreas. Boglino et al descreveram em criança de 11 meses a presença de um tumor palpável no abdome superior, que durante a cirurgia foi diagnosticado lipoma de cauda de pâncreas ${ }^{5}$.

$\mathrm{Na}$ abordagem deste caso, a tomografia computadorizada do abdome foi decisiva no diagnóstico. Devido ao tumor estar bem circunscrito e sem sinais de invasão, optaram pela realização da cirurgia com biopsia por congelação, não sendo realizados outros métodos mais invasivos, como a aspiração percutânea por agulha fina.

Baseado neste caso e nos descritos na literatura, podese concluir que a tomografia computadorizada é o exame que preenche os melhores critérios para o diagnóstico do lipoma do pâncreas. Embora outras doenças como a pseudo-hipertrofia lipomatosa e alguns tumores benignos e cistos das células pancreáticas possam apresentar características radiológicas que se assemelham ao lipoma, o estudo com TC sem a utilização da biopsia por agulha fina é suficiente para afastar o diagnóstico de adenocarcinoma do pâncreas.

\begin{abstract}
Intrapancreatic lipoma is an extremely rare neoplasm. The authors present a case of pancreatic lipoma in a 51years-old white female, with a history of abdominal pain for a twelve-month period, without other findings. Computed tomography scanning showed a $5 \mathrm{~cm}$ tumor located at the head of the pancreas. After surgical excision of a solid mass, histological study reveled a benign neoplasm of fat-cells, surrounded for normal pancreatic tissue. The authors comment on the more important aspects of this pathology.
\end{abstract}

Key words: Lipoma; Pancreas.

\title{
REFERÊNCIAS
}

1. Axelson J, Dawiskiba S, Akerman M et al. Connective Tissue Tumors. In: Howard J, Idezuki Y, Ihse I, Prinz R (eds). Surgical Diseases of the Pancreas. $3^{\circ}$ edition. USA: Williams \& Wilkins, 1998, pp 633-636.

2. Bigard MA, Boissel P, Regent D et al. Intrapancreatic lipoma: first case in the literature. Gastroenterol Clin Biol 1989; 13: 505-507.

3. Merli M, Fossati GS, Alessiani M et al. A rare case of pancreatic lipoma. Hepatogastroenterogy 1996; 43: 734736.

4. Katz DS, Nardi PM et al. Lipomas of Pancreas. Journal of the American Roentgen Ray Society 1998; 170: 14851487.
5. Boglino C, Inserra A et al. Lipoma intrapancreático: descrizione di un caso. Ped Med Chir 1993; 15: 397-399.

Endereço para correspondência: José Huygens Parente Garcia Rua Leonardo Mota, 1.750/700 60170-041 - Fortaleza-CE e-mail: huygens@secrel.com.br 